\title{
Advanced Digital Tools for Updating Overcrowded Rail Stations: Using Eye Tracking, Virtual Reality, and Crowd Simulation to Support Design Decision-making
}

\author{
Ming Tang ${ }^{1}\left[\right.$ C $\cdot$ Christopher Auffrey ${ }^{2}$
}

Received: 5 November 2018/Revised: 2 December 2018/Accepted: 8 December 2018/Published online: 19 December 2018

(C) The Author(s) 2018

\begin{abstract}
This paper describes an innovative integration of eye tracking (ET) with virtual reality (VR) and details the application of these combined technologies for the adaptive reuse redesign of the Wudaokou rail station in Beijing. The objective of the research is to develop a hybrid approach, combining ET and VR technologies, as part of an experimental study of how to improve wayfinding and pedestrian movement in crowded environments such as those found in urban subway stations during peak hours. Using ET analysis, design features such as edges, and color contrast are used to evaluate several proposed rail station redesigns. Through VR and screen-based ET, visual attention and related spatial responses are tracked and analyzed for the selected redesign elements. This paper assesses the potential benefits of using ET and VR to assist identification of station design elements that will improve wayfinding and pedestrian movement, and describes how the combination of VR and ET can influence the design process. The research concludes that the combination of VR and ET offers unique advantages for modeling how the design of rail transit hub interiors can influence the visual attention and movement behavior of those using the redesigned station. This is especially true for crowded conditions in complex interior spaces. The use of integrated ET
\end{abstract}

Ming Tang

tangmg@ucmail.uc.edu

1 School of Architecture and Interior Design, University of Cincinnati, Cincinnati, OH 45221-0016, USA

2 School of Planning, University of Cincinnati, Cincinnati, OH 45221-0016, USA

Communicated by Christopher Auffrey, Haishan Xia, Chun Zhang. and VR technology is shown to inform innovative design approaches for facilitating improved wayfinding and pedestrian movement within redesigned rail stations.

Keywords Urban rail station redesign - Eye tracking · Virtual reality $\cdot$ Wayfinding $\cdot$ Signage $\cdot$ Agent-based crowd simulation

\section{Background}

China is a world leader in the construction and use of urban rail networks. As a result of the large investments by Chinese cities in urban rail infrastructure over the past two decades, seven of the world's 12 largest subway systems are now located in China, with additional urban rail infrastructure planning and under construction [1]. The rapid rise in the use of urban rail transit in Chinese cities has created challenges in both providing new infrastructure and redeveloping existing infrastructure made functionally obsolete by increased numbers of passengers and rising expectations of the transit experience. To meet these challenges and take advantage of opportunities, there is a need for advanced design tools to better understand how redeveloped structures can better meet the needs of current and future demands. As such, these new design tools should support improved passengers' satisfaction with the facilities as well as address the impact of stations on the nearby communities where they are located [2].

This paper assesses how a combination of eye tracking (ET) and virtual reality (VR) can provide that innovative technology. ET devices measure eye position and eye movement, allowing documentation of how environmental elements draw the visual attention of viewers. Because of the cost and cumbersome equipment requirements of ET 
research, some wayfinding and signage researchers interested in how structural elements and signage capture human attention in the complex visual environment have used 3 M's Visual Attention Software (VAS) [3]. While validation studies have shown that VAS produces results consistent with eye tracking for static images, using it for assessing visual attention in dynamic contexts is cumbersome. Fortunately, in recent years there have been significant breakthroughs in eye tracking technology with new hardware and software applications able to measure continually changing fixation duration and gaze pattern as one experiences changing visual fields. Wearable eyetracking glasses with integrated video capture and VR headsets with advanced eye-tracking capability are now available at significantly lower cost.

To date, a number of studies using ET have concentrated on physiological measurements of eye movements and the process of transforming raw eye-tracking data into the higher-level constructs appropriate for analysis [4]. Zhang integrated ET with 3D point cloud data and VR to study the spatial behaviors and assist spatial design [5]. Similarly, Anders used ET to analyze architectural space communicated as space itself and its 2D representations [6].

Recent advances in VR technology also have been significant for its uses as a research design tool. Near-realistic graphics, full ET integration, and immersive advances have made the combination of ET and VR an especially useful tool for design researchers. Clearly, ET and VR have ascended beyond entertainment and evolved into an essential tool for architecture and urban planning practitioners. Research using these technologies has demonstrated their utility for designers in multiple ways [7]. The integrated uses of ET and VR are expanding and increasing considered essential research tools in the fields of visual systems, design, psychology, wayfinding, cognitive science, and marketing.

As with human behavior related to wayfinding and spatial cognition, signs and architectural motifs aid in navigation and invite viewers to experience space [8]. Rather than using assumptions based on generalized models, ET technology provides data about where human visual attention is actually drawn for specific users [9]. Using ET, designers can objectively measure where individuals actually look in space, and better utilize the five key visual elements known to draw human attention: faces, intensity, edges, blue-yellow contrast, and red-green contrast [10]. By integrating ET with VR, researchers can display immersive environments in VR and measure how elements of that environment capture viewers' attention. Also, researchers can use integrated technology to collect data from different viewers' navigational and visual attention experiences. In effect, the integrated ET and VR technology "gives life to a stationary design proposal."
Overall, based on experience using integrated ET and VR technology it was found that designers were able to understand how viewers visually experience of space without the limitations of two-dimensional drawings and renderings that can blur the line between representation and reality. As such, design flaws that could have never been found without the use of the integrated VR and ET technology can be readily identified. Further, the technology allows viewers to experience the designed space at full scale, something that before this technology was available, could happen only after a building or space was built or rebuilt.

\section{Rail Station Design}

In early 2018, a project team composed of architecture faculty and students at a major US university were assigned the task to design "the rail station/transportation hub of the future" using the emerging ET and VR technologies. The specific assignments were to improve the design of the existing Wudaokou (五道口) (WDK) subway station located in the Haidian District in Beijing, China. The station (Fig. 1) is on Line 13 and was opened in 2002. The station is close to the Beijing station of the Jingzhang railway, one of China's first railways, and scheduled to be demolished as part of urban redevelopment.

Beijing's Haidian District is the location of fourteen universities and multiple commercial centers. Given its location, the WDK station is one of Beijing's busiest and most crowded subway stations during morning and evening peak hours. During peak morning hours, 351 passengers entered the station and 1792 persons exited every $10 \mathrm{~min}$. During the peak evening hours, 894 passengers entered the station and 303 exited every $10 \mathrm{~min}$.

Since the WDK station was first opened, the population of Beijing has nearly been doubled, and current service demands and daily passenger volumes exceeded its built capacity [11]. The existing WDK station was not designed to accommodate current large number of departing and arriving passengers efficiently and needs to be rebuilt to accommodate current status as well as the expected substantial growth in passenger volume forecast over the next decade. Using data of maximum passenger volumes during the morning and evening peak hours, the project team sought to improve the efficiency of the wayfinding and circulation within the station. As such, a building performance analysis was conducted based on wayfinding in high-traffic zones.

In addition to improving the flow of arriving and departing passengers, the project team focused on making the redesigned station a destination for the surrounding neighborhood by creating a mixed-use hub that would 

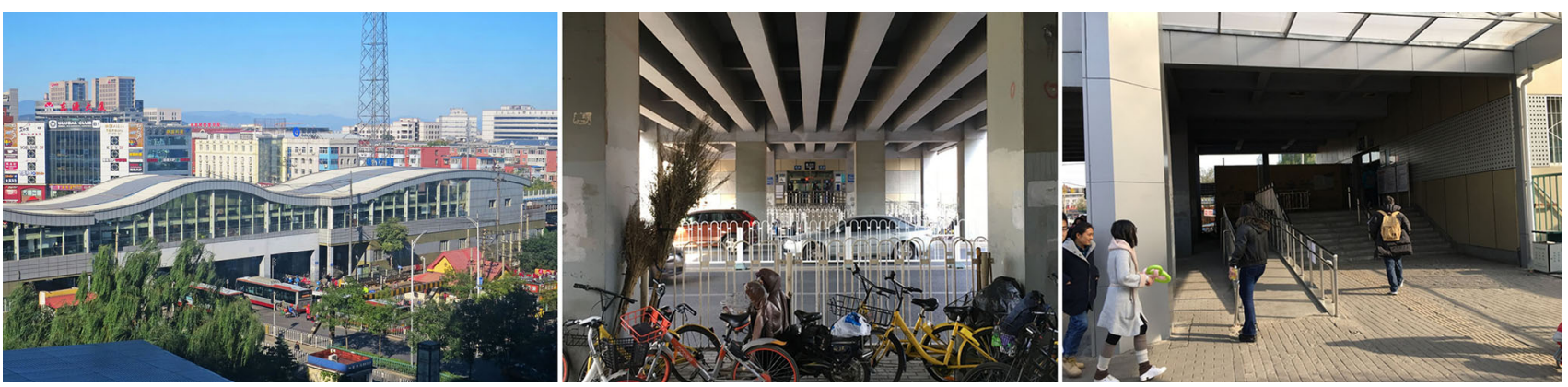

Fig. 1 Left—urban context of WDK station; middle — the roadway and sidewalks beneath the station; and right—-the entrance to the station

accentuate the already rich urban fabric of the area. As such, the team sought to move the larger numbers of passengers to and from the subway trains, and at the same time create an attractive mixed-use destination by providing high-quality public amenities accessible to subway passengers and non-subway passengers, alike.

\section{Assessment of Circulation, Signage, and Wayfinding}

Circulation is an essential function for public transportation structures such as subway stations. The project team understood that the new station must accommodate the circulation needs of both current and future users. To do this, the design process started with identifying major existing circulation-related site issues, including dark entrances and narrow spaces. These issues were assessed by analyzing how the station would be used in the future. It was determined that a larger building with wider hallways, stairs, and platforms could provide both short- and longterm improvement for both subway passengers and the WDK neighborhood more generally.

ET technology is an especially useful tool for assessing the effectiveness and need for station signage and wayfinding. Signage is a critical element of wayfinding for enclosed systems such as subway stations, and the design team sought sign designs and placements that facilitate wayfinding and result in more efficient circulation routes. When considering signage and other wayfinding elements, designers were informed by how users view space, and specifically by (1) primary eye focus points in the first few seconds of viewing; (2) areas of interest identified; and (3) the order of visual attention among the elements viewed.

\section{Use of Virtual Reality}

Based on the performance evaluation, the project team selected a preliminary design based on objective, quantitative criteria. Subsequently, crowd simulation tools using an agent-based method were used to analyze the wayfinding capabilities of the preliminary design, based on the researchers' previous experience using an agent-based simulation in combination with VR to investigate wayfinding behaviors in simulated environments [12].

Ultimately, the crowd simulation proved beneficial in assisting the team to understand how daily commuters would experience the spaces inside the station. Specifically, the crowd simulation and VR were helpful in determining the needed widths and lengths of corridors. It was calculated that an average of 1700 people would use the WDK station every $10 \mathrm{~min}$ during the peak hours. Taking into account the expected population and passenger volume increases over the next 25 years, the project team used the VR to analyze conditions in the station under extreme crowding. Examples showing the benefits of using VR include:

- Identifying the most common paths for passengers entering and leaving the station, and the primary modes of movement through the building. Results showed that by including multiple exit routes from the platform level, the building is more easily navigable on a routine basis as well as more quickly evacuated during emergencies such as a fire;

- In combination with crowd simulation, assessing how increasing the distances around stairways and elevators would reduce extreme congestion in the "bottlenecked" areas. This demonstrates how crowd behavior simulation can assist identification of circulation paths that may have been otherwise overlooked;

- Assessing how strategic placement of entrances, exits, and floor cutouts can minimize the congestion that slows the movement of people into or out of a station (Fig. 2). 

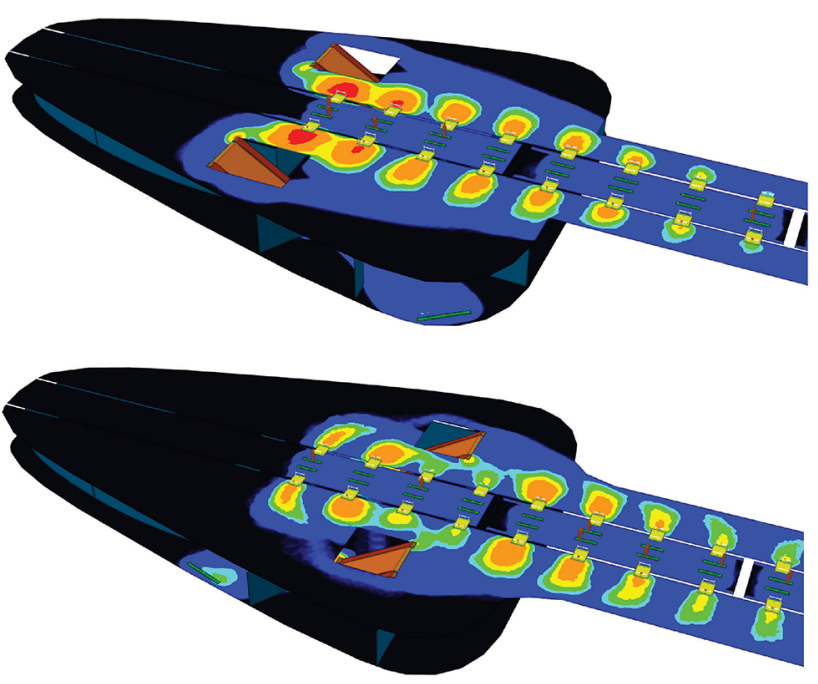

Fig. 2 Results of crowd simulation with agent-based modeling (top: entrances toward the end of subway platform create hot spots; bottom: entrances toward the middle of the subway platform create a better distribution of passengers and fewer hot spots). By Jordan Sauer

The technology was also used to assess the effectiveness of directional and wayfinding signage. An agent attention gaze map was used to analyze how to design and place signage that will best capture the visual attention of those moving through the station. It was found that signage placed in a vertical plane produced the best results for capturing visual attention. These results were later tested and validated using VR with integrated ET.

Other results from the VR model showed that many passengers will:

- Take the route of the shortest distance even when that route may take more time due to crowding;

- Block the space around the stairs and escalator while waiting for the next subway train, slowing or even blocking those seeking to depart the platform.

Based on the results of the VR and agent-based crowd simulation, designs were proposed to enlarge the subway platforms, widen the entrance/exit ramps, and increase the number of stairways and escalators (Fig. 3). The project team also found that some of their initial design ideas actually increased congestion, thereby they made improvement through a process of revising and reanalysis.

\section{Use of Virtual Reality with Integrated Eye Tracking}

The project team used ET in conjunction with VR to assess the effectiveness of the proposed design strategies. An eye fixation map was created to show where visual attention was focused. As shown in Fig. 4, passengers walking on the platform are expected to first look at video advertisements displayed on the platform level before glancing at advertisements on the train.

Similarly, the designers used ET to assess the wayfinding performance of the proposed station designs (Fig. 5). Based on the visual attention literature, the focus was on color contrast, edges, intensity, and face elements. A design was proposed that included a light blue ceiling, video walls with shades of black and bright reds, signage with a yellow-orange edge, and stairs placed near the entrance in plain sight.

\section{Assessing Other Auxiliary Components}

Through the analysis of eye fixation, areas of interest, and heat maps, the design team found that passenger visual attention could be effectively captured by using designs that include human faces and animal figures. To this end, a virtual zoo and other interactive experience were proposed to capture passenger visual attention within the rail station. The design assumes that in the future, technology such as augmented reality and holographic projections would become more commonplace (see Fig. 6 and Table 1).

The proposed virtual zoo depends upon the augmented reality (AR) and holographic projection technologies. When first entering a domed area of the station, a video of the African savannah, underwater ocean scene, or other pleasant viewscape would be projected on the ceiling using projectors installed around the perimeter of the space. The intent would be to provide a full 3D holographic visual experience without the use of special glasses. There is also the potential for the video to be live-streamed from any location on earth. It could become interactive with the programming of desired content. For example, as people enter the space, fish could swim away from them. This kind of real-time interaction brings a new reality to space. The animals, grass, and other elements would be part of the AR experience. The experience can be made educational as well as entertaining. It could be also something that many people living in large cities do not get to experience in real life [14].

An additional outcome of the ET analysis was the emphasis it gave color contrast sensitivity. Based on this finding, an information system using contrasting colors was 
Fig. 3 Subway platform congestion using VR and agentbased crowd simulation (left: crowd walking speed map; right: crowd density map)
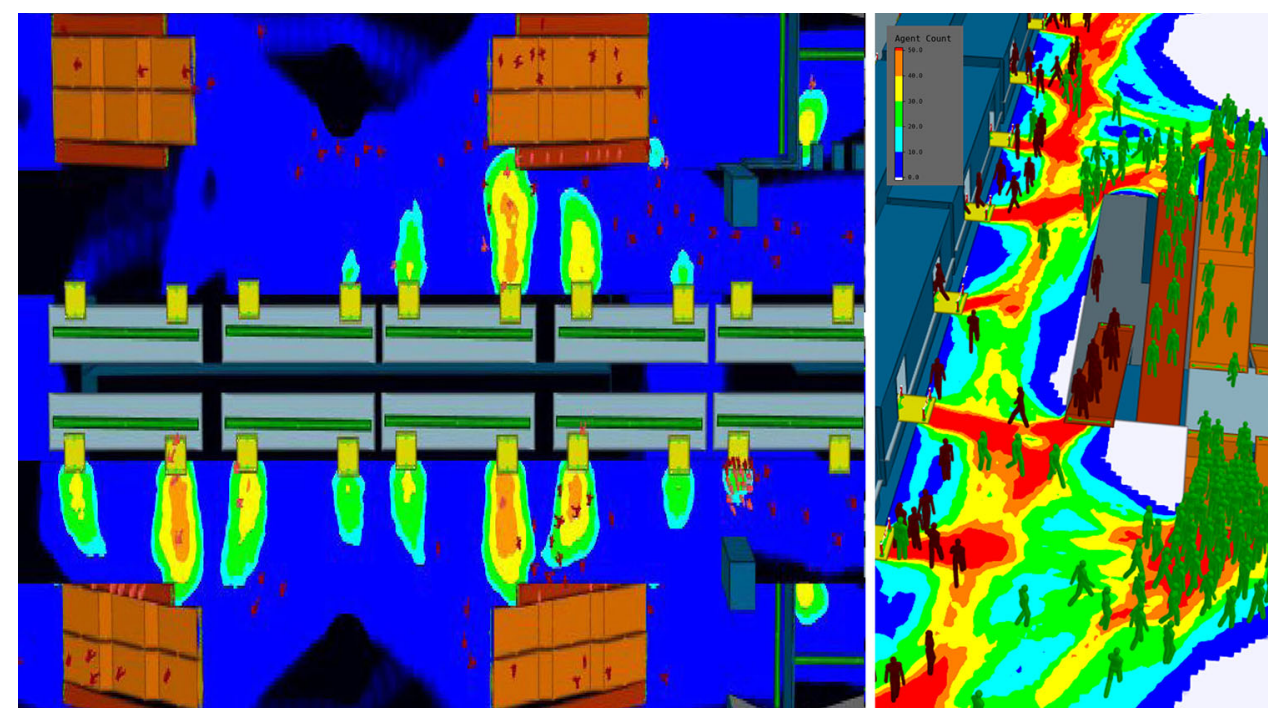
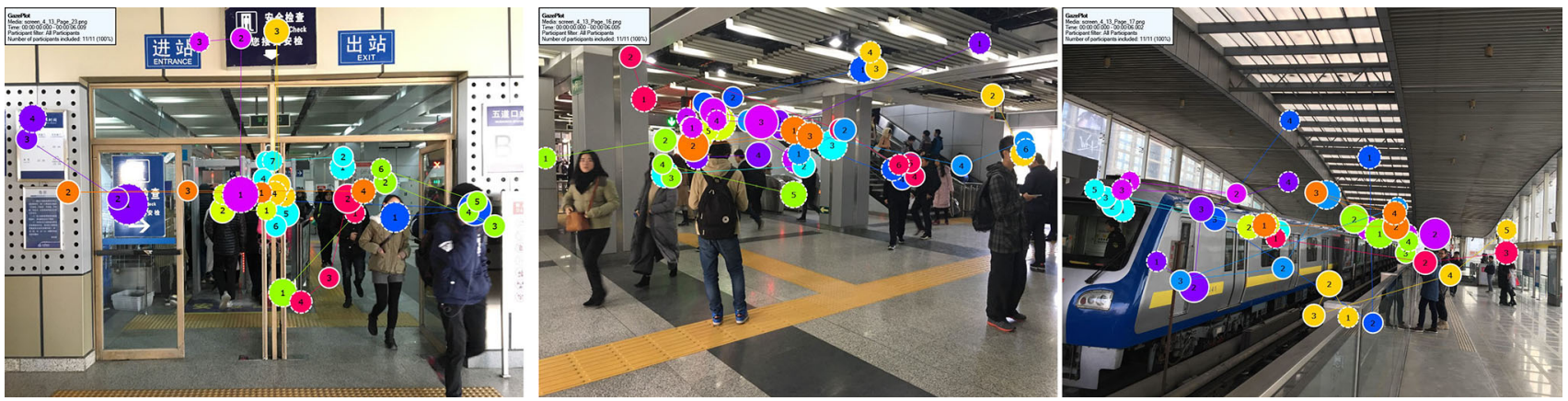

Fig. 4 Gaze plot map based on integrated ET with VR of the existing rail station

designed to show boarding passengers, which cars were most full, and which had the most space for additional passengers. The proposed design uses weight sensors and a color contrast displace board to convey where to stand on the boarding platform. The weight of each train car is measured as it arrives, reflecting how many passengers are inside. This information is processed into color values and displayed on the panel above the platform [15].

Additionally, weight sensors could be placed in the platform corresponding to the number of passengers waiting at different places along the platform. As passengers waiting to board move about the platform, the panel colors could reflect the spatial balance between the number of waiting passengers and available train car space (Fig. 7).

\section{Conclusions}

"If a picture is worth a thousand words, then how much more is a video or VR?" This comment from a member of the project team reflects the growing importance of VR as a design tool, especially when combined with emerging technologies such as ET. This is especially important for understanding and responding to the dynamic environments of urban rail stations. The designers' ability to immerse themselves and interact with elements of their urban rail station redesigned was greatly enhanced by having access to these digital design tools.

The design experience described in this paper has established for the authors that creating a walkthrough in VR and then testing that design in ET give the designer both the freedom and power to test design concepts, by which they can identify and fix problems. Throughout the design process, the project team was able to validate their design strategies, e.g., creating a wider platform, which was conclusively shown to enhance passenger movement through the station and even facilitate use the stairs or escalators without a high level of congestion.

One team member described the need for and benefits of the visual feedback from ET and VR, noting that "I realized that too many visual stimuli in the immediate entrance were disorienting. The ET proved to be beneficial in that I was able to watch exactly how someone might experience the space [12]." 

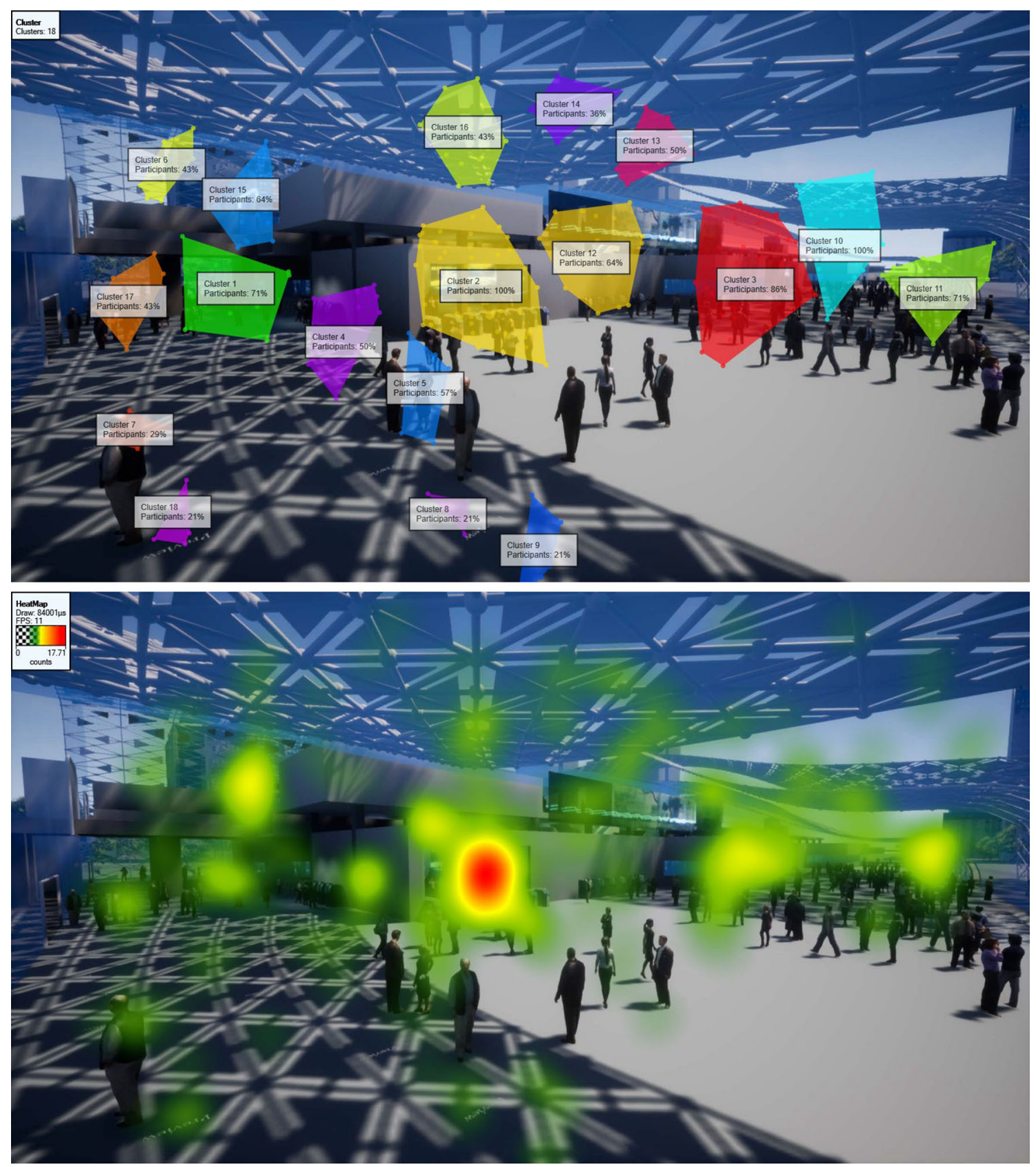

Fig. 5 Heat map and area of interest generated using VR with integrated ET. By Dongrui Zhu [13]
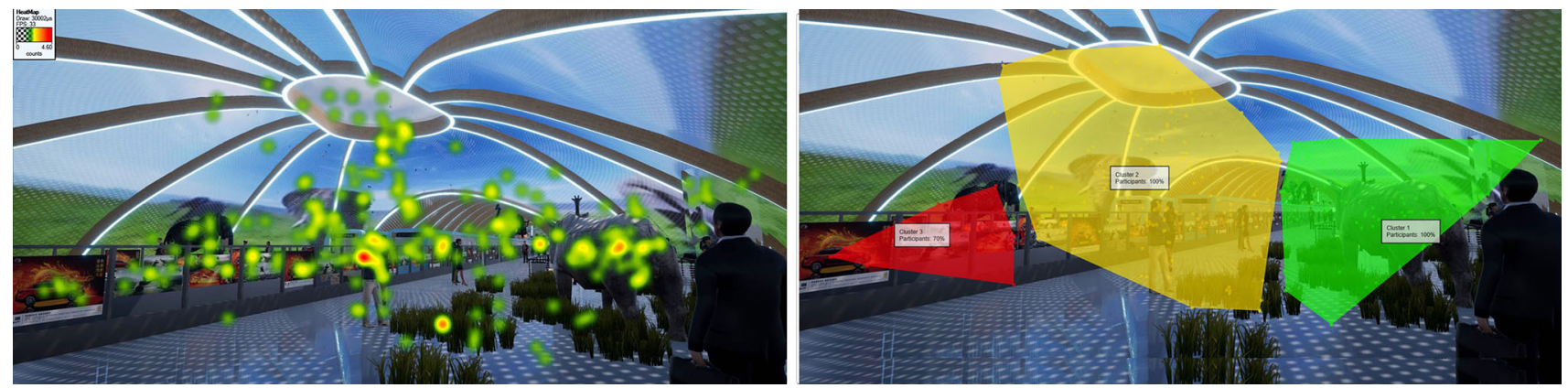

Fig. 6 Analysis of the proposed virtual zoo using VR with integrated ET (left: visual fixation heat map; right: areas of interest for ET analysis). By Jordan Sauer 
Table 1 Time (seconds) to first fixation based on three areas in Fig. 6. Cluster 1: green color AOI; cluster 2: yellow color AOI; cluster 3: red color AOI

\begin{tabular}{|c|c|c|c|c|c|c|c|c|}
\hline Record & Cluster 1_mean & Cluster 1_sum & Cluster 2_N & Cluster 2_mean & Cluster 2_sum & Cluster 3_N & Cluster 3_mean & Cluster 3_sum \\
\hline 1 & 3.29 & 3.29 & 1 & 0 & 0 & - & - & - \\
\hline 1 & 0.84 & 0.84 & 1 & 0.26 & 0.26 & 1 & 2.97 & 2.97 \\
\hline 1 & 1.08 & 1.08 & 1 & 0.11 & 0.11 & 1 & 3.18 & 3.18 \\
\hline 1 & 0.03 & 0.03 & 1 & 0.48 & 0.48 & 1 & 2.88 & 2.88 \\
\hline 1 & 5.57 & 5.57 & 1 & 0.17 & 0.17 & - & - & - \\
\hline 1 & 0 & 0 & 1 & 0.32 & 0.32 & 1 & 1.01 & 1.01 \\
\hline 1 & 1.04 & 1.04 & 1 & 0.2 & 0.2 & 1 & 3.87 & 3.87 \\
\hline 1 & 0 & 0 & 1 & 0.32 & 0.32 & - & - & - \\
\hline 1 & 3.08 & 3.08 & 1 & 0 & 0 & 1 & 0.17 & 0.17 \\
\hline 1 & 4.84 & 4.84 & 1 & 0 & 0 & 1 & 1.42 & 1.42 \\
\hline 10 & 1.98 & 19.76 & 10 & 0.19 & 1.85 & 7 & 2.22 & 15.51 \\
\hline
\end{tabular}
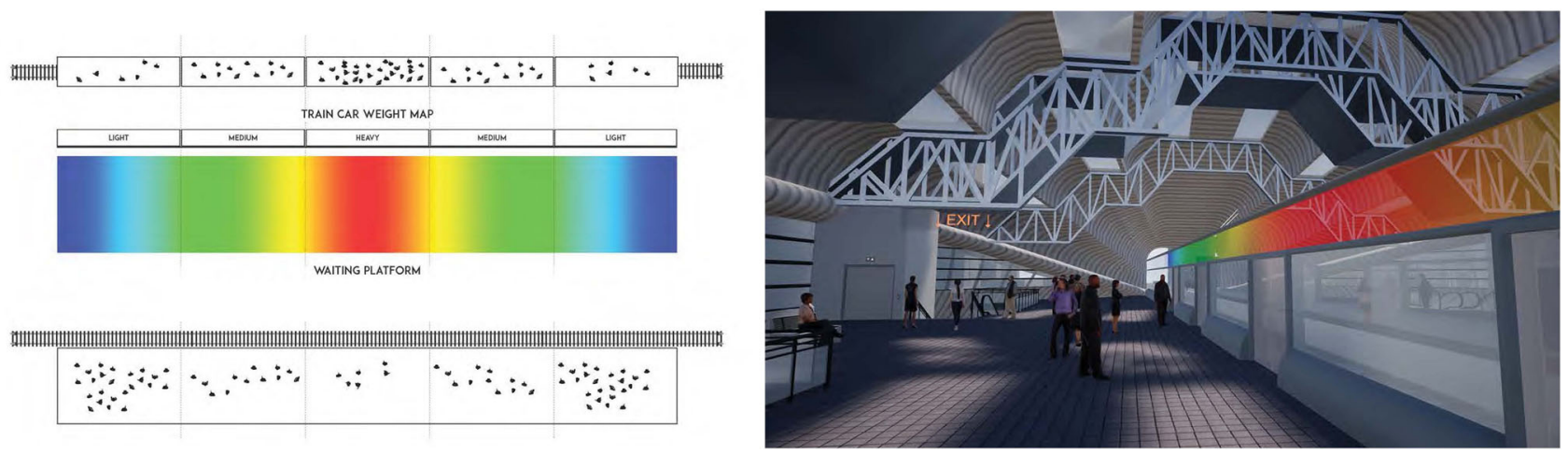

Fig. 7 Placement of color contrast information panel to guide boarding (left: color contrast system to guide passengers for boarding; right: placement of information panel). By Tyler Dunn

Another team member said, "Without these technologies, it would have been reckless to guess how the pedestrian flow would occur throughout the station... Human scale and the human experience are the most important part of building design, and by using human simulation (through VR) the design can truly be put to the test [12]."

Still, a third team member commented on the impact of these emerging technologies saying "I believe that the architecture field as a whole, both in academic and professional settings, is moving towards the more regular use of VR and ET technologies, as there are undoubtedly significant benefits to its usage in visualizing and marketing design. The ability to put on a headset and fully be immersed in design is one that is not possible using simple drawings and renderings, and one that often results in a better response from clients in the professional world [12]."

While the use of VR and ET has many advantages, they are not without their additional costs. An important consideration in the use of VR and ET is the high level of design detail required. Typically, architects or planners present $2 \mathrm{D}$ drawings and sometimes a small physical or digital model reflecting basic conceptual issues. The use of VR and ET forces the designer to control and be aware of many more aspects of the building, including furniture, fixtures, lighting, vegetation, and people. The extent to which these and other related design elements are developed or not developed may alter the VR experience and ultimately change the results of ET analysis.

Open Access This article is distributed under the terms of the Creative Commons Attribution 4.0 International License (http://crea tivecommons.org/licenses/by/4.0/), which permits unrestricted use, distribution, and reproduction in any medium, provided you give appropriate credit to the original author(s) and the source, provide a link to the Creative Commons license, and indicate if changes were made. 


\section{References}

1. Slater M (2018) The 10 biggest China metro systems. China Checkup. https://www.chinacheckup.com/blogs/articles/chinametro-systems. Accessed 22 Oct 18

2. Wu R (2018) Passenger experience of China's high-speed rail service. Open J Soc Sci 6:253-259

3. Auffrey C, Hildebrandt H (2014) Utilizing 3 M's visual attention service software to assess on-premise signage conspicuity in complex signage environments. In: Proceedings of the national signage education and research conference

4. Medina E, Cuddihy E, Goldberg E, Ramey J (2008) Uses of eye tracking technology in design. Proc Hum Factors Ergon Soc Annu Meet 52(19):78-1574

5. Zhang L (2018) "Integration of virtual reality, 3-D eye-tracking, and protocol analysis for re-designing street space." In: Fukuda T, Huang W, Janssen P, Crolla K, Alhadidi S (Eds.) Learning, adapting and prototyping, proceedings of the 23rd CAADRIA conference, vol 1, pp 431-440

6. Hermund A (2018) The perception of architectural space in reality, in virtual reality, and through plan and section drawings - a case study of the perception of architectural atmosphere. In: Kepczynska-Walczak A, Bialkowski S (Eds.) Computing for a better tomorrow-proceedings of the 36th ECAADe conference, vol 2, pp 735-744

7. Soler JL, Ferreira J, Contero M, Alcañiz M (2017) The power of sight: using eye tracking to assess learning experience (LX) in virtual reality environments. In: INTED2017 proceedings, pp 8684-8689
8. Tang M (2018) From agent to avatar-integrate avatar and agent simulation in the virtual reality for wayfinding. In: Fukuda $\mathrm{T}$, Huang W, Janssen P, Crolla K, Alhadidi S (Eds.) Learning, adapting and prototyping, proceedings of the 23rd CAADRIA conference, CAADRIA, 2018, vol 1, pp 503-512

9. Kiefer P, Giannopoulos I, Raubal M, Duchowski A (2017) Eye tracking for spatial research: Cognition, computation, challenges. Spat Cogn Comput 17(1-2):1-19

10. Auffrey C, Hildebrandt H (2017) Do motorists see business signs? Maybe. Maybe not. A study of the probability that motorists view on-premise signs. Interdiscip J Signage Wayfinding 1(2): 100

11. Chen F, Wu Q, Zhang H, Li S, Zhao L (2009) Relationship analysis on station capacity and passenger flow: A case of Beijing subway line 1. J Transp Syst Eng Inf Technol 9(2):93-98

12. Tang M (2018) Eye-tracking analysis for train station. ARCH 4002 studio student reflection. School of Architecture and Interior Design, College of DAAP, University of Cincinnati. Students: Anna Kick, Ashna Podar, Connor Kramer, Dongrui Zhu, Bhattiprolu Snigdha, Gabriel Berning, Michael Geer, Issac Keller, Jordan Sauer, Mason Boiling, Nathan Reilly, Owen Blodgett, Ruby Qiu, Tyler Dunn, Edward Simpson. Faulty: Ming Tang, Xiaoying Meng

13. Dongrui Zhu (2018) Train station design proposal. ARCH4001 studio, University of Cincinnati

14. Jordan Sauer (2018) Train station design proposal. ARCH4001 studio, University of Cincinnati

15. Tyler Dunn (2018) Train station design proposal. ARCH4001 studio, University of Cincinnati 